Advances in Geosciences, 6, 1, 2006

SRef-ID: 1680-7359/adgeo/2006-6-1

European Geosciences Union

(c) 2006 Author(s). This work is licensed

under a Creative Commons License.

\title{
Foreword
}

\section{1st Alexander von Humboldt International Conference}

This special volume of Advances in Geosciences contains papers presented during the 1st Alexander von Humboldt International Conference on "The El Niño Phenomenon and its global impact" held in Guayaquil, Ecuador 16-20 May 2005. This conference was the first of a series of Alexander von Humboldt (AvH) conferences initiated by the European Geosciences Union (EGU),international and interdisciplinary meetings related to geoscience topics of particular importance to South America, with global impacts as well. It was jointly organized by the International Research Center on El Niño (CIIFEN) in Guayaquil and EGU experts. CIIFEN, was inaugurated in 2003, in response to several resolutions of the United Nations General Assembly; and is supported by the World Meteorological Organization (WMO), the International Strategy for Disaster Reduction, and the Governments of Ecuador and Spain. CIIFEN's Mission is "to contribute to the comprehension of $\mathrm{El}$ Niño-Southern Oscillation (ENSO) and climate variability as well as its effects, through basic and applied research, generating products to promote decision making, plans and policy to support society in risk reduction to ENSO towards a sustainable development". This First AvH International Conference on ENSO and its global impact was held under the patronship of Klaus Toepfer, Executive Director of the United Nations Environment Program (UNEP). It was highly interdisciplinary in dealing with ENSO in all aspects related to the Ocean, Atmosphere, Climate, Biology and Human Dimensions, its impact in South America and teleconnections worldwide. During the 5 days' meeting the following topics, introduced by Keynote papers, were discussed: The ENSO Phenomenon; ENSO in Climate History(all time scales including Palaeo-ENSO); Recent major ENSO events and their Impacts in South America, on Marine Biology and Terrestrial Ecosystems, and the interaction with the Pacific Decadal Oscillation (PDO); Teleconnections and Worldwide Impacts; ENSO Prediction; ENSO and Global Warming; and Socio-Economic Aspects. More than 150 scientists from 40 countries participated in this meeting whose interdisciplinary mix turned out to provide an exciting atmosphere stimulating fruitful discussions. The organizers (now in the role as guest editors of this proceedings volume) are grateful to EGU and WMO for financial support, to CIIFEN and many local helping hands for a perfect organization. They like to particularly acknowledge the stimulating presentations of the Keynote Speakers and the excellent contributions of experts from all over the world.

José Luis Santos, Past Director-CIIFEN

Peter Fabian, Vice-President EGU

Special Volume Editors 